\title{
A Sectoral Eco-Efficiency Analysis on Urban-Industrial Symbiosis
}

\author{
Yuli Bian ${ }^{1}$, Liang Dong $2,3, * \mathbb{C}$, Zhaowen Liu ${ }^{4}$ and Lezhu Zhang ${ }^{1, *}$ \\ 1 College of Economics and Management, South China Agricultural University, Guangzhou 510642, China; \\ bylscau@gmail.com \\ 2 Department of Public Policy, City University of Hong Kong, Kowloon 999077, Hong Kong, China \\ 3 School of Energy and Environment, City University of Hong Kong, Kowloon 999077, Hong Kong, China \\ 4 Faculty of Civil Engineering and Geosciences, Delft University of Technology, 2628CN Delft, \\ The Netherlands; z.liu-8@tudelft.nl \\ * Correspondence: liadong@cityu.edu.hk (L.D.); lzzhang@scau.edu.cn (L.Z.)
}

Received: 20 March 2020; Accepted: 29 April 2020; Published: 1 May 2020

check for updates

\begin{abstract}
Urban-industrial symbiosis (UIS) is an important system innovation via sectors integration, and has been widely recognized as a novel pathway for achieving regional eco-industrial development. Eco-efficiency, as a mature approach and indicator, offers an effective tool to uncover both the status and trends of such a transformation. However, most studies have focused on the whole industry or city as a whole, which has meant that a view from the sectoral level focusing on UIS was missing. To fill this research gap, this paper applied a modified eco-efficiency approach using integrating input-output analysis (IOA) and carbon footprint (CFP) to identify the eco-efficiency benefits of UIS from a sectoral level. Specifically, sector-level economic data (as economic outputs) and CFP (as environmental impacts) are used to calculate the sectoral eco-efficiency. IOA helps to offer sectoral economic data, and, with integrating process-based inventory analysis, to conduct a CFP calculation at the sectoral level. To test the feasibility of the developed approach, urban industrial symbiosis scenarios in one typical industrial city of China were analyzed. This city is held up as the national pilot of the circular economy, low-carbon city, and ecological civilization in China. Scenarios analysis on a business as usual (no UIS) and with UIS implementation in 2012 were undertaken and compared with the change of sectoral CFP and eco-efficiency. The results highlighted a moderate increase in eco-efficiency and trade-offs in certain sectors, indicating that UIS was moderately effective in increasing the urban resource efficiency from a sectoral level, but a refined design was required. Policy recommendations are made based on the analytical results, to inform decision makers and urban and industrial managers seeking to improve the implementation of UIS as a means of achieving greater urban sustainability.
\end{abstract}

Keywords: urban-industrial symbiosis; urban sustainability; eco-efficiency; carbon footprint; China

\section{Introduction}

The city is a critical element to realize the sustainable development goals (SDGs) [1]. Urban sustainability aims to enhance environmental quality, social equity, and economic prosperity in an urban context $[2,3]$. To realize the target of urban sustainability, we need a systematic approach and pathway, to tackle the multiple challenges in urban contexts, such as urban population explosion and urban sprawl, industrial pollution, poor quality of life, and intensive resource consumption and emissions $[4,5]$.

Urban industrial symbiosis (UIS) offers such a pathway to some extent. It refers to the synergies between industrial processes, as well as the integration of industrial sectors and urban areas, in the way 
of resources, wastes, and by-products exchanges $[6,7]$. By utilizing wastes to save raw materials and fuels, UIS can significantly improve resource efficiency [8,9]. Particularly, by strengthening the reuse and recycle of wastes and by-products (substitution of wastes), as well as by reducing the materials consumption at source, UIS plays a role to strengthen the circular economy in the waste hierarchy. Hence, it is widely recognized as an important system innovation to realize the circular economy, and a novel pathway towards eco-efficiency enhancement and regional eco-industrial development $[10,11]$. Emerging studies have highlighted how industrial symbiosis, or UIS, played a role to strengthen urban resource management and urban sustainability [12-14]. However, quantitative studies, which offered evidence on how such practices lead to urban environmental impacts (e.g., carbon dioxide $\left(\mathrm{CO}_{2}\right)$ emissions) mitigation, have been less reported.

In addition, in the sectoral level, UIS actually improves the material and energy flows and the resources efficiency in the processes, and the whole supply chains, according to the above feature $[15,16]$. Hence, it will be valuable to explore the sectoral efficiency change under UIS. Eco-efficiency, which is defined as "economic output" per "unit environmental impacts" [17,18], offers a mature indicator applied to analyze the ecological and economic efficiency improvement in a certain system. However, most eco-efficiency studies had focused on technological systems or cities as a whole [19-21]; few studies of how the implementation of UIS generated impacts on sectoral eco-efficiency have been reported. To explore and present the inter-sector relationship is critical to support such study, and the input-output analysis (IOA), which enables to uncover such intra-sector information [22-24], and helps to calculate carbon footprints (CFPs) as a key environmental indicator [25-27], therefore will be a potential sound method to resolve the above question. However, related studies have been rarely done yet.

Based on this background and highlights on the scientific questions, this paper aims to investigate the eco-efficiency benefits of UIS from a sectoral level. To support this analysis, a modified eco-efficiency approach integrating input-output analysis (IOA) and carbon footprint (CFP) was developed. In the approach, sector-level economic data as economic output, and CFP as environmental impact were applied to calculate the sectoral eco-efficiency. In return, their changes reflected the contribution of UIS on sectors and intra-sectors. In the model integration scheme, IOA offers sectoral economic data, combined with integrating process-based inventory analysis, to conduct CFP calculation in the sectoral level. To test the feasibility of the developed approach, UIS scenarios in one typical industrial city of China were analyzed. The city is highlighted as the national pilot of a circular economy city, low-carbon city, and ecological civilization in China. Our past studies already included some fundamental research on this case city: we applied an IOA approach to analyze the life cycle benefits of UIS [24] and we did CFP calculations on the city and rough sectoral (five sectors) level [17]. Based on this foundation, this paper outlines our follow-up research with focuses on sectoral eco-efficiency assessment. We applied the modified eco-efficiency approach to analyze 13 sectors to see how the eco-efficiency changed under UIS scenarios in detail. Scenarios analysis on business as usual (no implementation of UIS), and with various UIS implementations in 2012 were conducted and compared with the change of sectoral CFP and eco-efficiency. Policy recommendations are made for a better implementation of UIS as urban system innovation.

The following parts are organized as follows: after the introduction section, Section 2 describes the concept of urban sustainability and UIS, and displays how UIS will contribute to urban sustainability; Section 3 describes the general research framework, model integration scheme, methodologies and data source for this study; Section 4 presents the case condition; Section 5 displays the analytical results and discussions; and finally, the conclusions and corresponding policy implications are made in Section 6.

\section{Urban Industrial Symbiosis as a Solution Towards Urban Sustainability}

Urban industrial symbiosis is one key component of the industrial ecology (IE) discipline, combining industrial symbiosis and urban symbiosis. The concept of industrial symbiosis (IS) refers to a relationship that industries within a certain geographical scope use to conduct interfirm 
resource sharing $[28,29]$. By sharing material, energy, and/or by-products in a mutually beneficial way, the efficiency of resource utilization is able to be improved [30,31]. Urban symbiosis is an extended concept of IS, referring to resource sharing in urban and industrial areas with geographic proximity [32]. By innovatively utilizing urban wastes into industry, resource efficiency can be enhanced and the related environmental impacts can be reduced. Particularly, urban municipal solid waste can be utilized by nearby industry, and industry can provide urban areas with living necessities, e.g., hot water and steam [33-35]. With UIS, a harmonious relationship between cities and industry could be achieved and the environmental impacts can be reduced accordingly. Particularly, from a regional planning perspective, urban industrial symbiosis offers a planning strategy to better locate facilities and infrastructure by considering the optimized underlying material and energy flows (illustrated as Figure 1).

\section{Urban-industrial system innovation}

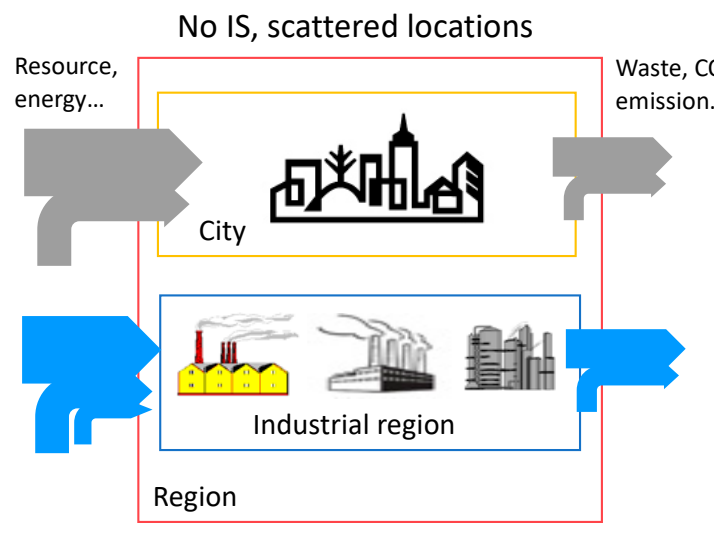

Urban system material/energy flows

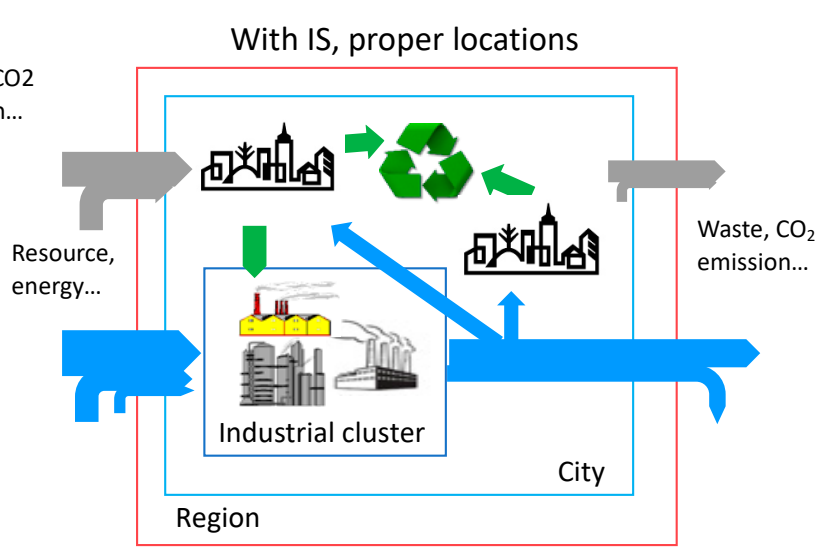

Industrial system material/energy flows

Figure 1. Image of flows optimization by urban industrial symbiosis (IS). Source: revised from the authors' previous study [24].

According to the above description of urban industrial symbiosis, it provides an innovative pathway to advance urban transition, from a mass production and consumption format to an ecologically harmonious eco-city stage. As Figure 2 illustrates, urban sustainability relates to urban resources and efficiency. With the limitations of the former, how to enhance efficiency is critical. Urban industrial symbiosis provides guidance to properly locate the urban space, industrial facilities, and infrastructure, with better design on the underlying flows optimization in the whole network. This way, it is expected to enhance the system efficiency, so as to finally support higher urban sustainability. The following section will conduct an analysis to visualize such benefits.

To test this hypothesis on urban sustainability transition, China offers an ideal laboratory, with its rapid and intertwined urbanization and industrialization, and corresponding series of sustainable urban projects to advance an urban transition towards sustainability. Particularly, since the 12th five-year plan (FYP), China had begun to apply great effort to promote the new economic mode highlighted as "Ecological Civilization", which emphasizes realizing the final goal of social and environmental reform within a prosperous society [36]. In 2012, the Communist Party of China (CPC) officially included the goal of achieving an ecological civilization in the national constitution, as well as being featured in the FYP [1]. Ecological industries and ecological cities are clearly emphasized as the key component of the ecological civilization strategy in the emerging economic development stage [16]. Amongst these projects and initiatives, a circular economy and urban industrial symbiosis are key measures to contribute, but to date, few studies have been conducted to verify the effects of the projects' promotion. 
With this circumstance, based on a local project, this study applied the developed approach into one typical industrial city of China, named Guiyang, in Guizhou province, which is highlighted as the national pilot of circular economy city, low-carbon city, and ecological civilization in China. With such features, the case study not only tested the feasibility of the method and verified the model, but also offers critical insights for policy implications.

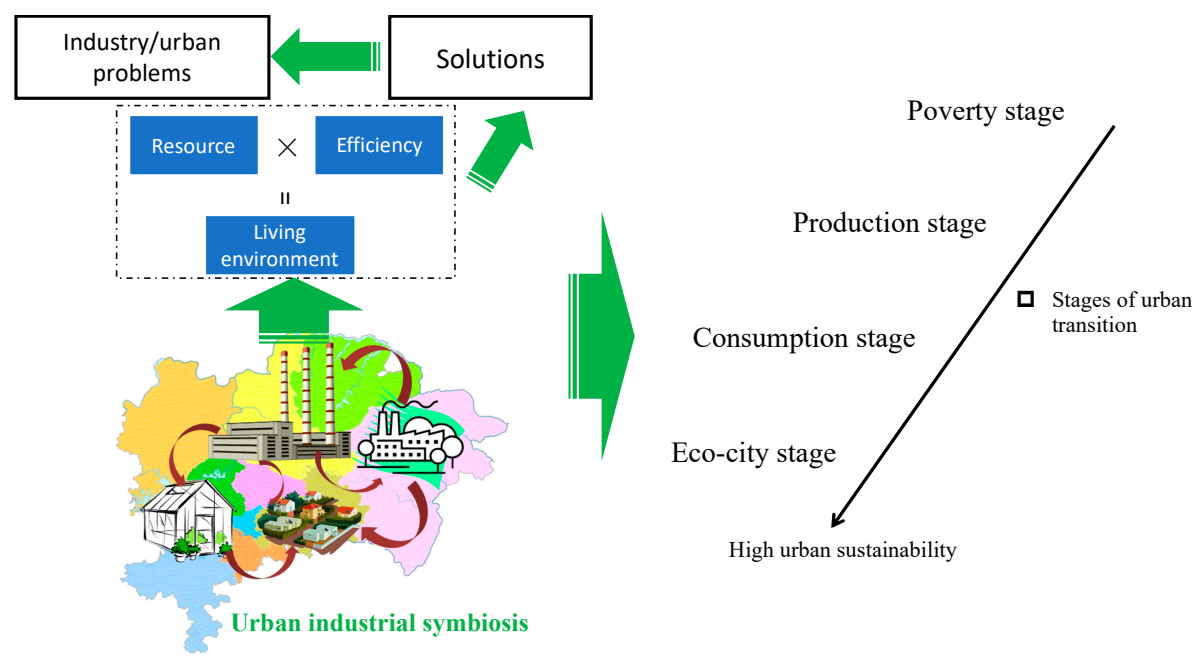

Figure 2. Urban transition strategy by enhancing system efficiency. Source: the authors' previous study [17].

\section{Materials and Methods}

\subsection{Research Framework}

Research framework is illustrated in Figure 3:

- First of all, we conducted the environmental system analysis, to analyze the general resources consumption, waste generation, economic outputs in urban and sectoral level, and material flows related to UIS system, to provide the environmental data as the foundation for the further analysis on the sector-level eco-efficiency.

- Secondly, IOA was applied to calculate the sector-level CFPs and provide sector-level economic data; these two parts were the elements used to calculate the sectoral eco-efficiency (Equation (1) describes in detail). IOA results were conducted based on various scenarios' design in 2007 and 2012. Equations (2) to (4) describe this in detail.

- Based on step 1 and step 2, sector-level environmental inventory analysis was done after the projection of UIS scenarios, e.g., in sectoral level, resources consumption change and waste generations change were investigated under the UIS scenarios. Such environmental data change helped to calculate the change of sector-level eco-efficiency. Equations (5) and (6) describe this in detail.

- Finally, sectoral eco-efficiency was calculated based on the value of sector-level CFPs and economic outputs, under various scenarios (with and without UIS projection). In this way, how the UIS could impact the eco-efficiency was able to be investigated. The change of eco-efficiency could be seen as some contribution of UIS to the urban transition towards sustainability. 


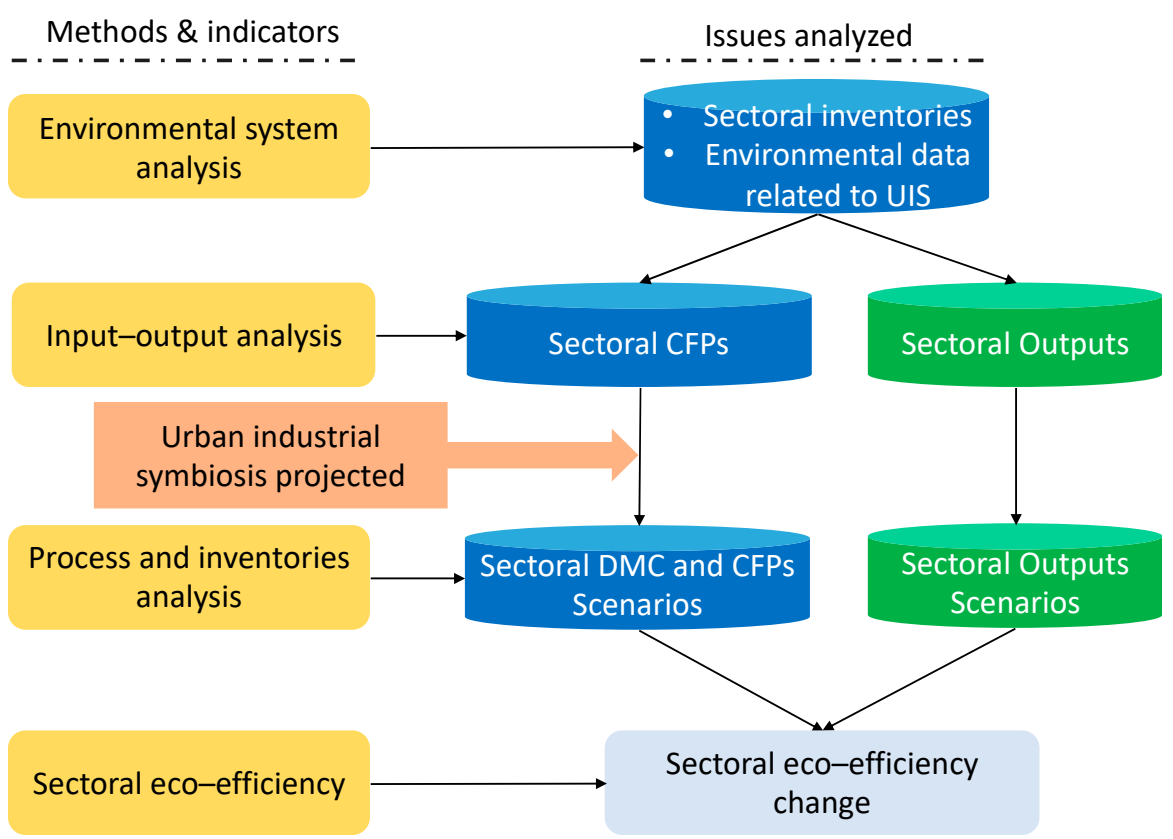

Figure 3. Research framework. Abbreviations: UIS—urban-industrial symbiosis, CFP—carbon footprint, DMC-domestic materials consumption.

\subsection{Sectoral Eco-Efficiency Indicator}

Eco-efficiency is a mature indicator used to analyze the ecological and economic efficiency improvement in a certain system such as products, sectors, or cities. Here we apply a modified eco-efficiency based on Equation (1):

$$
E E=\frac{\text { Economic Output }}{\text { Environmental impact }}
$$

where, $E E$ is eco-efficiency; economic output will be quantified by sectoral economic output (CNY); and environmental impact will be expressed by sector-level CFPs (ton $\mathrm{CO}_{2} \mathrm{eq}$ ). The change of $E E$ hereby was able to measure the cost and benefit of application of UIS to different sectors.

\subsection{System Boundary and Model Integration Scheme}

The system boundary is described in Figure 4. Traditional processes from resource mining to the final waste landfill can be seen as the business as usual scenario. The UIS scenarios changed the flow with various methods of resource/energy recycling, reuse, and recovery. Therefore, the system included both the process and industrial/urban system. For the former, the metabolism could be analyzed with process-based inventory analysis, e.g., material flow analysis; for the latter, input-output analysis (IOA) investigated the impacts in urban scale. The monetary matrix in the input-output table, which shows how output from one sector becomes an input to another sector, depicts inter-sector relationships within an economy in monetary value. In addition, because in the IOA, it assumed uniform products (same product means same price) from each sector; the monetary input-output relationship could further present the physical input-output relationship. In this way, the inter-sector matrix is able to present the inter-sector technological relations.

The sectoral inventories (environmental data) together with sector economic output, constructed the coefficients matrix, which helped to calculate the sectoral environmental outputs (e.g., CFP) with consideration of the inter-sector linkage presented by the input-output matrix. 


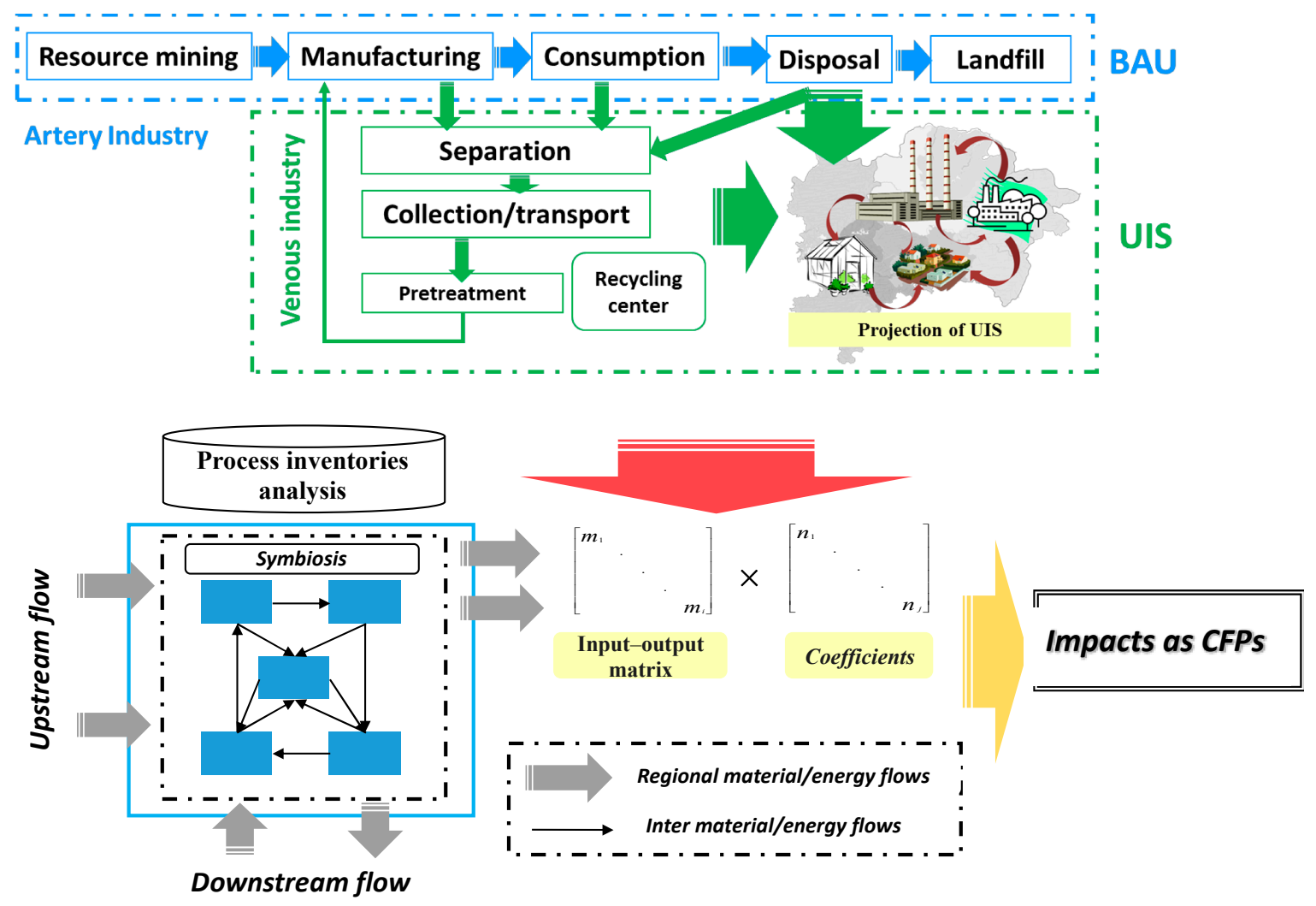

Figure 4. System boundary and model integration scheme. Source: revised from the authors' article: [12]. Abbreviation: BAU-business as usual.

Based on the above description on the system boundary, inventory analysis for sectors on the related materials, energy flows, and corresponding emissions was done to compile the sectors' inventory data, and as a foundation to investigate how UIS activities would cause changes to certain sectors and certain material, energy, and emissions. Based on the inventory analysis, IOA was integrated with process analysis by providing sectoral input-output data matrix as well as upstream and downstream flows information. In detail, the production structure matrix represented by input-output tables (IOTs) presented the relationship among sectors, and the final demand matrix in IOTs offered the information of the final consumption in the market. The environmental coefficient matrix helped to quantify the carbon emissions per unit (per unit CFPs). In this way, the CFP in terms of direct and indirect emissions associated with urban industrial symbiosis activities was able to be investigated.

\subsection{CFPs Evaluation}

While the sectoral economic output statistics were available, calculation of CFPs was assisted by IOA. This study followed our previous studies $[17,24]$ to calculate the CFPs, which is defined as direct and indirect $\mathrm{CO}_{2}$-equivalent emissions from socioeconomic and human activities within certain boundaries (e.g., nation, region, city) $[37,38]$. We applied the previously built IOA approach to calculating life cycle impacts and CFPs. We had already done some fundamental work on the case city: we applied IOA approach to analyze the life cycle benefits of UIS [24] and CFP calculation on the city and rough sectoral (five sectors) level [17]. Based on this foundation, this paper applied the new established sectoral eco-efficiency assessment to investigate the detailed sectoral information. We apply the modified eco-efficiency approach to analyze 13 sectors, to see how the eco-efficiency changed under UIS scenarios in detail.

IOA is a mature and prevailing tool to investigate the linkages between different sectors, in the economic system $[23,24]$. To apply the IOA into CFP's evaluation at an urban level, in which IOTs 
are usually unavailable, province-level IOTs were applied. The basic structure of IOT is illustrated in Table 1, and the key mathematical functions are described as follows.

Table 1. Conceptual framework of input-output analysis (IOA) model.

\begin{tabular}{cccc}
\hline & Intermediate Output & Final Demand & Total Outputs \\
\hline Intermediate input & $A x$ & $f$ & $x$ \\
Value added & $v$ & & \\
Total inputs & $y$ & & \\
\hline
\end{tabular}

The complex economic relations within the economic system is expressed by the production structure matrix in IOA. Basic IOA approach is presented in Equations (2) and (3):

$$
\begin{gathered}
x=Z+f=A x+f \\
x=(I-A)^{-1} f
\end{gathered}
$$

where $x$ is the output of economic system, which is the sum of intermediate consumption among different sectors, $Z=A x$, and the final consumption $f$. The $A$ matrix is the direct consumption matrix, which indicates the interrelation between each sector of the economy, e.g., input from sector $i$ to sector $j$, to generate the corresponding output for sector $j$. In this way, A will present a technical coefficient matrix to describe the interlinkage of each sector in the economic system. Equation (2) can be further transformed into Equation (3), where matrix $I$ is the identity matrix (value is unified as 1), and $(I-A)^{-1}$ is the Leontief inverse matrix.

Based on this basic IOA analytical process, the calculation of sectoral emission contributions was further done based on an environmentally extended input-output (EEIO) approach, which was well established in previous studies $[3,12,17,24]$. The details are: based on the sectoral inventory analysis, we decided the $\mathrm{CO}_{2}$ emission of sectors, and via this, economic outputs could be further be coupled with sectoral emissions. With normalization process between the sectoral emissions and

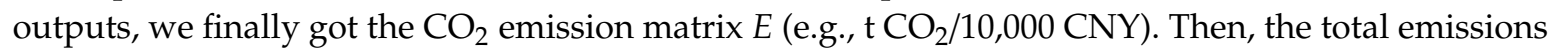
under a given final demand, was able to be calculated following Equation (4). Where $e$ is the whole supply chain's $\mathrm{CO}_{2}$ emissions (or so-called CFPs in this study) to meet the final demand $f$ in our economic system.

$$
e=E(I-A)^{-1} f
$$

In the above methods, we linked the impacts of a certain sector to related sectors. As introduced, the inter-sector monetary matrix was able to present the technological relations of sectors. The sectoral inventories (environmental data) together with sector economic output constructed the coefficients matrix (e.g., $E$ in Equation (4)), which helped to calculate the sectoral environmental outputs with consideration of the inter-sector linkage presented by the input-output matrix. In this way, when any UIS drove some change in the environmental data, such change could be further reflected by the input-output relations (e.g., how the change in sector 1 drove change in sector 2). Hence, can help to present the effects of UIS on various related sectors in the whole supply chain of the economic system.

Finally, to link the material/energy consumption change related to the urban industrial symbiosis, and get the detailed inventory data of each sector, process analysis was done. The overall sectoral inventory data like fossil fuels consumed and resources inputs was gained from local statistics. As to the analysis on how urban industrial symbiosis would affect the sectoral consumption, the following process analysis was conducted.

To each single process, the material/energy balance was made, following the process balance of: input $=$ output + intermediate emission (to the environment or other process). 
According to the process balance model, synergies (symbiosis between companies or sectors) could be analyzed. The effects of urban industrial symbiosis could be analyzed as follows, for the company or sector $i$ :

$$
\begin{gathered}
E n v G_{i j}=R_{i j} \text { or } W_{i j} \\
R_{i j}=S_{j} \times M_{i j}
\end{gathered}
$$

where $E n v G_{i}$ presents the resources saving or emissions mitigation for the company $i . R_{i j}$ represents resources saving while $W_{i j}$ represents the waste reduction via symbiotic activity. $j$ is the type of resource or waste. $R_{i j}$ means the multiplication of the resource substitution rate $\left(S_{i j}\right)$ and the quantity of reused/recycled materials $\left(M_{i j}\right)$. $W_{i j}$ means the quantity of the utilized waste (reuse, recycle, or use waste as resource) $j$. After exploring such process change related to urban industrial symbiosis, the inventories data change for each sector could be analyzed by allocating each category of resources/fuels into the proper sectors.

\subsection{Data and Materials}

According to the methods described, two kinds of data were required: IOT to build the IOA, and data of UIS.

Usually, the cities will not compile the IOT, hence, in this study, we borrowed the common way that utilized province-level IOT to build city-level IOT. We used IOTs in Guizhou province, in which the case city is the capital city, and combined with local official statistics to compile the case city's IOT. IOTs were aggregated to the same level of detail. IOTs in 2002, 2007, and 2012 were used, in the format of 42 sectors.

To get the sectoral energy inventory and emissions coefficients, we used the Energy Statistic Yearbook (ESY), which structured sectors similarly to the IOTs. We further aggregated the 42 sectors into 13 more integrated sectors to compile the energy data, presented in Table 2.

The second part was the data related to urban industrial symbiosis, which are generally more difficult to obtain. Data applied in this paper were mainly from the survey via the local project in Guiyang. The main data collection was via first-hand survey to local companies and agencies, described in our previous studies $[15,22]$. We conducted the survey with about 50 industrial companies, for example, iron/steel plant, cement company, phosphorus chemical company, and so on. In total, there were about 100 questionnaires sent for data collection, in terms of environmental, waste, and basic economic data. Complementary data was also gathered from a technical report on industrial level recommended emerging technologies, such as the circular economy technologies inventories recommended by central and local governments $[18,24]$. The baseline year of data collection was 2012, in order to match the IOTs application for further analysis.

\begin{tabular}{|c|c|c|c|}
\hline Sectors & Abbreviation & Sectors & Abbreviation \\
\hline 1-Agriculture & AGR & \multirow{3}{*}{$\begin{array}{l}\text { 16-Machinery and equipment } \\
\text { 17-Transport equipment } \\
\text { 18-Electric equipment and machinery } \\
\text { 19-Electronic and telecommunication } \\
\text { equipment } \\
\text { 20-Instruments, meters, and cultural } \\
\text { and office machinery } \\
\text { 21-Crafts and other manufacturing } \\
\text { 22-Waste recycling and treatment }\end{array}$} & \multirow{3}{*}{ IN_OTHMNUH } \\
\hline $\begin{array}{l}\text { 2-Coal mining and processing } \\
\text { 3-Crude petroleum and natural } \\
\text { gas products } \\
\text { 4-Metal ore mining } \\
\text { 5-Non-ferrous mineral mining }\end{array}$ & MIN & & \\
\hline $\begin{array}{l}\text { 6-Manufacture of food products } \\
\text { and tobacco processing }\end{array}$ & IN_FD & & \\
\hline \multirow{2}{*}{$\begin{array}{l}\text { 7-Textile goods } \\
\text { 8-Apparel, leather, furs, down, } \\
\text { and related products } \\
\text { 9-Sawmills and furniture }\end{array}$} & \multirow[t]{2}{*}{ IN_LIG } & $\begin{array}{l}\text { 23-Electricity, steam, and hot water } \\
\text { production and supply } \\
\text { 24-Gas production and supply } \\
\text { 25-Hot water production and supply }\end{array}$ & PP \\
\hline & & 26-Construction & $\mathrm{CON}$ \\
\hline
\end{tabular}

Table 2. Sectors aggregation. 
Table 2. Cont.

\begin{tabular}{|c|c|c|c|}
\hline Sectors & Abbreviation & Sectors & Abbreviation \\
\hline $\begin{array}{l}\text { 10-Paper and products, printing } \\
\text { and record medium } \\
\text { reproduction }\end{array}$ & IN_PAP & $\begin{array}{l}\text { 27-Transport and warehousing, post } \\
\text { and telecommunication }\end{array}$ & TRNS \\
\hline $\begin{array}{l}\text { 11-Petroleum processing } \\
\text { and coking } \\
\text { 12-Chemicals }\end{array}$ & IN_CHEM & \multirow[b]{3}{*}{$\begin{array}{l}\text { 28-Postal industry } \\
\text { 29-Information transmission, } \\
\text { computer services and software } \\
\text { industry } \\
\text { 30-Wholesale and retail trade } \\
\text { 31-Accommodation and catering } \\
\text { 32-Financial industry } \\
\text { 33-Real estate } \\
\text { 34-Leasing and business services } \\
\text { 35-Research and experimental } \\
\text { development } \\
\text { 36-Integrated technology services } \\
\text { 37-Water, environment, and public } \\
\text { facilities Management } \\
\text { 38-Resident services and other } \\
\text { services } \\
\text { 39-Education } \\
\text { 40-Health, social security, and social } \\
\text { welfare } \\
\text { 41-Culture, sports, and entertainment } \\
\text { 42-Public management and social } \\
\text { organization }\end{array}$} & \multirow[b]{3}{*}{ RES-SERV } \\
\hline 13-Nonmetal mineral products & IN_NMMI & & \\
\hline $\begin{array}{l}\text { 14-Metals smelting and pressing } \\
\text { 15-Metal products }\end{array}$ & IN_MMI & & \\
\hline
\end{tabular}

\section{Introduction to the Case City}

To identify the effects of urban industrial symbiosis, and to test the feasibility of our developed method, one typical industrial city named Guiyang was selected as the case city. It is highlighted as the capital of Guizhou province, and particularly, belongs to China's national pilots of the circular economy city and the low-carbon city. In addition, its economy depends heavily on the material processing industries like iron/steel, aluminum, cement, coal chemical, and phosphors chemical industry [15,22]. With this circumstance, it offers an ideal laboratory to investigate the promotion of urban industrial symbiosis. The location information is illustrated in Figure 5.

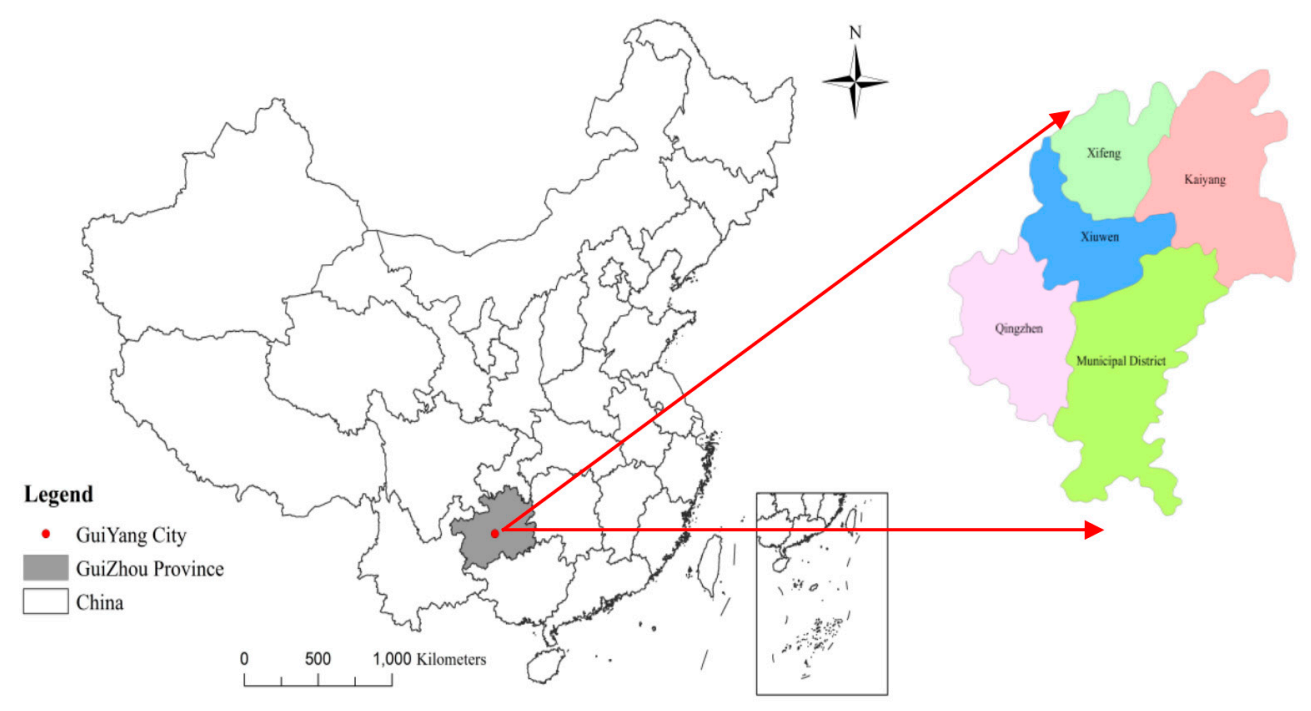

Figure 5. Geographical information of Guiyang city in China. 
Similar to many Chinese typical industrial cities, the case city has been promoting rapid economic growth, urbanization, and industrialization, as well as the underlying intensive resource exploration, consumption, and waste generation. Figure 6 shows the general trends of resource consumption and waste generation in recent years. A general increasing trend can be observed, indicating the increasing impacts on the local environment. These environmental data further helped us to do the sector inventory analysis, as well as build the business as usual scenario for the analysis.
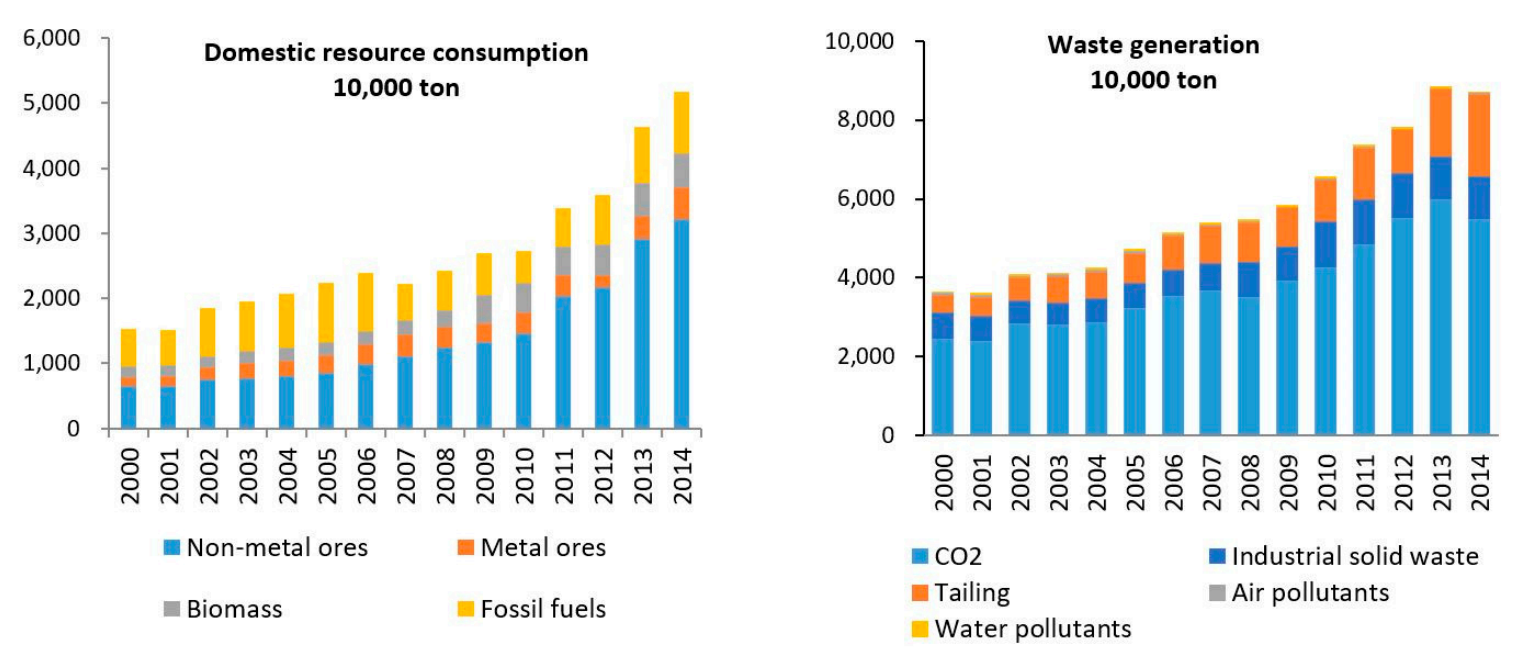

Figure 6. Resource consumption and waste generation in Guiyang, 2000-2014. Source: the author compiled the environmental data from local statistics, revised from the figure in the authors' article [17].

Finally, according to the city's industrial features, it has a high potential to form UIS, but until now, only bulky industrial waste recycling, e.g., slag recycling, had been promoted. This study designed a more integrated UIS network and analyzed its impact on the sectoral eco-efficiency.

\section{Results and Discussions}

\subsection{Scenarios Setting}

Based on the established methods, and the information from the case city, we set various scenarios to investigate the benefits of UIS on the city's sectoral eco-efficiency. For the scenarios' design, 2012 was the key year for comparison. To support the comparison, the following scenarios were set:

a. baseline scenario, which means a start-up scenario with no technical advancement and implementation yet, in the year of 2002 (BL2002);

b. business as usual (BAU) scenario, indicating the change from regular technological advancement, and normal economic growth, indicating the comparable scenario for implementation of UIS (BAU2007 and BAU2012) (to test the benefit of IS, we assume there was no industrial symbiosis in the business as usual scenario, even though some were already implemented at that time); and

c. scenarios indicating the implementation of several UIS options based on the local condition in the year of 2012 (UIS2012). 


\subsection{Design of Urban Industrial Symbiosis Scenarios}

The urban industrial symbiosis was designed according to local conditions and supply-demand matches based on technical conditions. Considering the industrial symbiosis, which focuses on the resource/waste exchange among industrial plants and sectors, the bulky solid wastes that could be utilized are as follows. (1) Slags from iron and steel plants, aluminum processing industry, phosphorus chemical industry, and power plants could be recycled and utilized in the cement sector to produce certain types of cement and construction materials, via this way, raw materials like lime could be significantly reduced. (2) Waste heat from manufacturing processes could be utilized by other plants (for example, aluminum and chemical plants) and for co-generation. As to the urban industrial symbiosis, which focuses on the municipal solid waste utilization by industrial sectors and resource/energy provision from industries to urban areas, they include: waste plastic recycling to the furnace of iron/steel plant and cement plant, in this way, fossil fuels could be reduced; industrial waste heat provision to nearby residential and commercial areas, and for co-generation as well; and waste steel recycling, which is rather traditional symbiosis format. Our previous works $[3,8,12,14,18,22]$ collected detailed technical information for the related waste recycling and energy recovery, with which scenarios can be designed in line with the practical conditions.

The design on UIS is illustrated in Figure 7 with a general calculation of the total CFPs in the city under the scenarios. The detailed materials and energy flows are presented in Supplementary Materials in the appendix. Particularly, to support more detailed analysis on UIS, we focused on analyzing the CFPs related to various types of UIS, such as:

a. bulky industrial solid waste recycling and exchange, e.g., coal flying ash (for this part, some slag (e.g., steel slag recycling at the scale of 30,000 ton/year) and coal flying ash recycling (around 50,000 ton/year) were already implemented in Guiyang city in 2012, but not at a large scale. Here we assumed an enlarged scale according to the technical parameter calculation (refer to Supplementary Materials);

b. traditional waste recycling, like the urban steel recycling, to substitute higher energy consumption in fresh steel making from iron ores (for this part, steel recycling was already implemented in Guiyang city in 2012, but not at a large scale (around 30,000 ton/year). Here we assume an enlarged scale according to the technical parameter calculation (refer to Supplementary Materials);

c. urban symbiosis, which links the industrial and urban sectors together to exchange waste, e.g., waste plastics or other municipal solid waste can be recycled and incinerated in the furnaces of a steel company, helping to reduce fossil fuels consumption for the furnace, like coke (for this part, they are a new design for Guiyang from 2012.);

d. finally, waste heat utilization, that is, making the industrial sectors play the role of heat provider to nearby urban and agricultural sectors, e.g., central heating systems, green houses and so on, to reduce fossil fuels consumption by households, commercial and agricultural sectors (for this part, they are a new design for Guiyang from 2012.). 

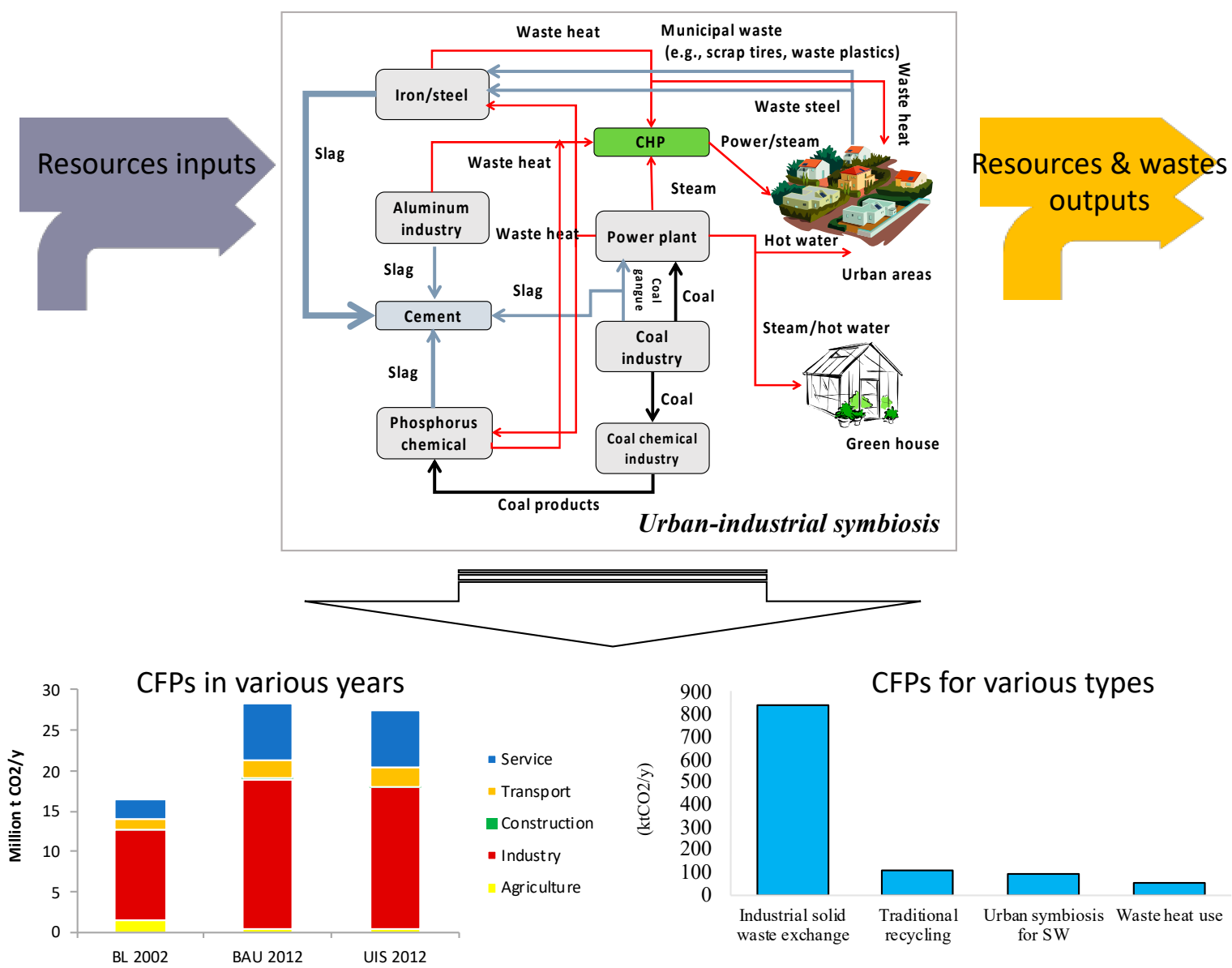

Figure 7. UIS design in Guiyang, and general CFPs calculation. Source: revised from the authors' paper [17]. Abbreviations: $\mathrm{CHP}-\mathrm{Co}$-generation heating plant, SW—Solid waste.

\subsection{Scenarios Analysis}

\subsubsection{General Analysis on City Level}

Based on the established model and symbiosis network design, urban CFPs were used as the baseline, the BAU scenarios and scenario with urban industrial symbiosis were firstly evaluated as foundational (Figure 7).

From the perspective of total urban CFPs within the time span, the total CFP of Guiyang city changed from 16.5 million $\mathrm{t} \mathrm{CO}_{2}$ in BL2002, to 28.4 million $\mathrm{t} \mathrm{CO}_{2}$ in BAU2012. As this paper focuses on the sectoral eco-efficiency, hence here we only present the general results of CFPs in the whole city and the most general sector perspective (agriculture, industry, construction, transport, and service). In the BL2002 scenario, CFPs of agriculture, industry, construction, transport, and service were 1.54, $11.08,0.02,1.30$, and $2.56 \mathrm{Mt} \mathrm{CO}_{2}$ /year, respectively. In BAU2012, the numbers changed into 0.39, $18.57,0.08,2.31$, and $7.04 \mathrm{MtCO}_{2}$ /year, respectively. Apart from the agriculture sector, all the other sectors' CFPs significantly increased, which is in line with the rapid industrialization and economic growth in Guiyang in this 10-year span (2002-2012). For developing countries like China, with rapid industrialization and economic growth, it is inevitable to increase the absolute value of energy consumption and CFP, despite the promotion of technological advancement and cleaner production. Under such conditions, how to find opportunities to realize a further CFP mitigation, for example, by innovating the supply chain, is critical. UIS actually is such a solution.

The UIS2012 scenario was further compared with BL2002 and BAU2012. Particularly, comparison with BAU2012 revealed the extra benefits of promoting urban industrial symbiosis. It is highlighted that, compared with BAU2012, the CFPs of UIS2012 reduced by $1.09 \mathrm{Mt} \mathrm{CO}_{2} /$ year, taking account of 
$3.63 \%$ of total CFPs in BAU2012, which is a relatively significant reduction effect. The result highlights the low-carbon benefits of urban industrial symbiosis promotion.

For each type of UIS, in general, compared with the whole urban level, they present relatively low emissions. For the industrial solid waste recycle and exchange, traditional waste recycling, urban symbiosis and waste heat utilization, the CFP accounts to about $840,110,94$, and 49 thousand tons $\mathrm{CO}_{2} / \mathrm{y}$, respectively.

\subsubsection{Sectoral Eco-Efficiency Analysis}

Based on the above total value of CFPs in the case city, sectoral CFPs with and without-UIS scenarios were calculated and compared.

Several critical insights were uncovered. First of all, due to surging economic growth and rapid industrialization (a common process in nearly everywhere of China), CFPs had increased a lot from 2002 to 2007 and 2012, particularly in industrial sectors. Secondly, since 2005 (11th FYP), China strengthened environmental regulation, and had achieved significant outcomes. At the same time, many measures have been taken, including the upgrading of clean technologies, enforced pollution control and energy conservation regulation, economic structure adjustment, and general technical and productivity efficiency enhancement. The surging final demand scale, to some extent, offset the projected resources and energy saving and CFPs mitigation, resulting in the continuous increasing of CFPs from 2002 to 2012. It requires an internal innovation to further reduce the environmental impacts for the system. In this regard, UIS offers an internal sectors' innovation to optimize the resource and energy loops among sectors, via material, waste, and by-product exchange, and recycling. From a supply chain perspective, one sector's mitigation will reduce the related resources saving and emissions from other sectors, hence a chain effect happened and life cycle $\mathrm{CO}_{2}$ emissions were reduced. This explained the result in Figure 8: with the implementation of UIS, CFPs reduced from $28.4 \mathrm{Mt}$ to 25.7 Mt. In the future, if there is a rational expansion of UIS with engagements of more sectors in the supply chain, even larger benefits of CFPs mitigation are expected.

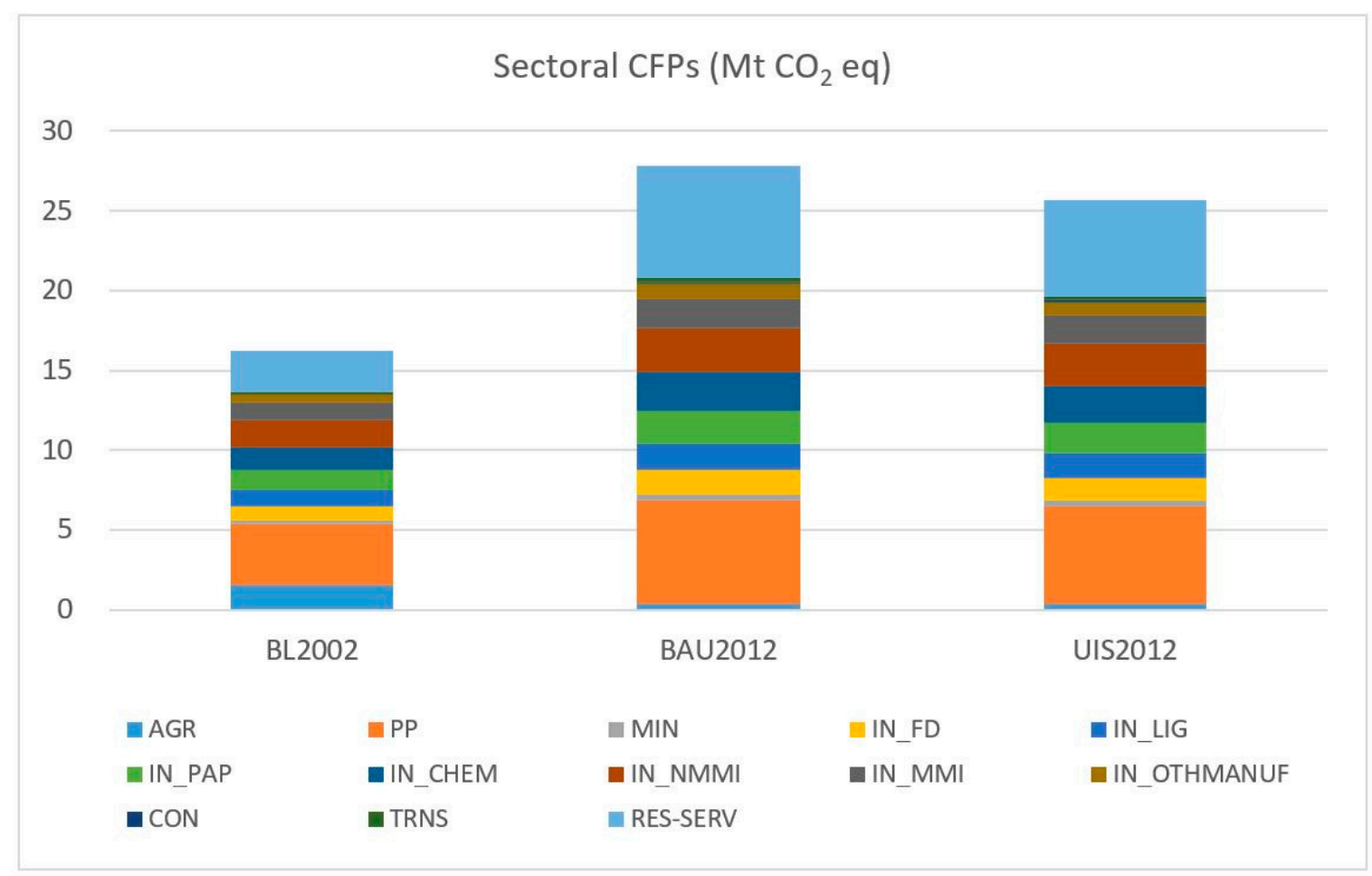

Figure 8. Sectoral CFPs calculation. 
According to the sectoral CFPs, sectoral eco-efficiency was calculated and analyzed. Critical insights were uncovered via looking into the general trend and sectoral details. As Figure 9 illustrates, compared with BL2002, in BAU2007, even though the environmental impacts like the CFPs had increased a lot with even more fast economic output growth, as well as the economic structure adjustment, eco-efficiency still increased. At this stage, pollution control and technologies efficiency enhancement had large space to reduce the resource and energy consumption, as well as the corresponding CFPs together with fast economic growth. From 2007 to 2012, the sum of sectoral eco-efficiency was nearly the same, but if we exclude the construction sector, we can still observe that most industrial sectors still increased the eco-efficiency to some extent. In this stage, on the one hand, the CFPs mitigation space from pure technological efficiency enhancement had become much smaller (as technological efficiency enhancement had limitations); on the other hand, after the 2008 financial crisis, to tackle the economic challenges, the government expended the development of real estate and related construction sector in a not very rational way, resulting to the decrease of eco-efficiency of the construction sector. Meanwhile, many polluted small and medium industrial plants reopened to offset the employment challenges, also causing negative impacts on the sectoral and total eco-efficiency. Due to this, a new CFPs mitigation space was required from system innovation, and UIS was one answer.

\section{Sectoral eco-efficiency $\left(10,000 \mathrm{CNY} / \mathrm{t} \mathrm{CO}_{2}\right)$}

40

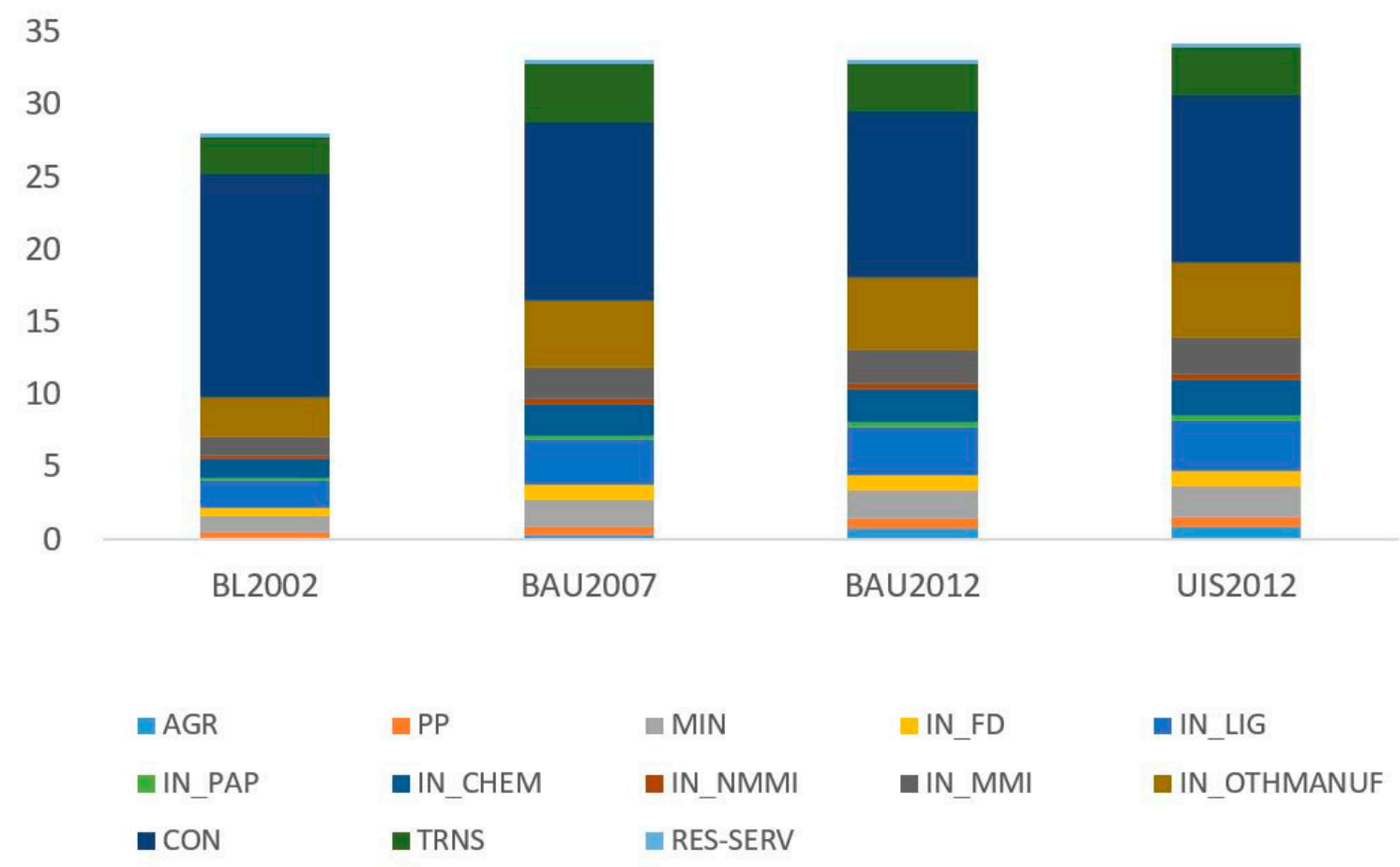

Figure 9. Sectoral eco-efficiency change.

With the comparison of UIS2012 and BAU2012, an increase on the sectoral eco-efficiency was found, even though the increase scale was small, as the projection scale of UIS was relatively small compared with the whole urban system. UIS not only brought the direct sectoral CFPs to certain sectors engaged in the symbiosis network, but also generated the CFPs mitigation for the sectors in the whole supply chain.

Finally, Figure 10 presents the detail sectoral CFPs and eco-efficiency. The larger the size of the box means a larger value of eco-efficiency. Several findings are highlighted. 
- It is well known that IOA is consumption-based approach, which, can uncover the embodied CFP related to the final demand and the service section. That is why apart from the power generation sector (largest coal consumer. In addition, Guiyang city, and Guizhou province, is main power supplier in China to nearby areas.), service sector accounts for the large value of CFP. Also, the metal and non-metal metallurgy industry, and the chemical industry are also large contributors to CFP. This is in line with the local industrial feature; they are the pillar industries in Guiyang city. Such findings can offer insights for Guiyang to set the priorities for a CFP mitigation strategy. The consumption-based evidence (findings on service sector) can also indicate that we can further to reduce the sectoral CFP by optimizing the consumption structure and lifestyle improvement.

- When we see the issue of sectoral eco-efficiency, eco-efficiency of the construction sector is the largest, mainly due to the reason that, first of all, construction contributes to the added value of real estate; higher economic output increases the eco-efficiency. It should also be noted that, in the supply chain, the real environmental impacts from construction sector are not large, but there are large indirect impacts generated from the up-stream sectors supporting the real estate industry to develop, like the iron and steel industry, cement industry, and so on.

- It should also be highlighted that the pillar industries in Guiyang city-power industry, metal and non-metal metallurgy industry, and chemical industry (for example, phosphorus chemical)—actually present relatively low eco-efficiency. This is caused by relative low value added and high CFP (high energy consumption). On the other hand, such industries have high potential to implement industrial symbiosis and the circular economy, hence in the future, the industries managers should keep promoting UIS in such industries to enhance their eco-efficiency. In addition, to increase the products' added value is also a critical way to enhance eco-efficiency, hence, to extend the industrial chains and innovate the final products is important.

- What's more, by revealing such detailed sector information, we can further adopt rational and proper UIS to certain sectors to generate better life cycle benefits, finally to realize a second-round sectoral CFPs mitigation and eco-efficiency enhancement.

Sectoral CFPs UIS2012
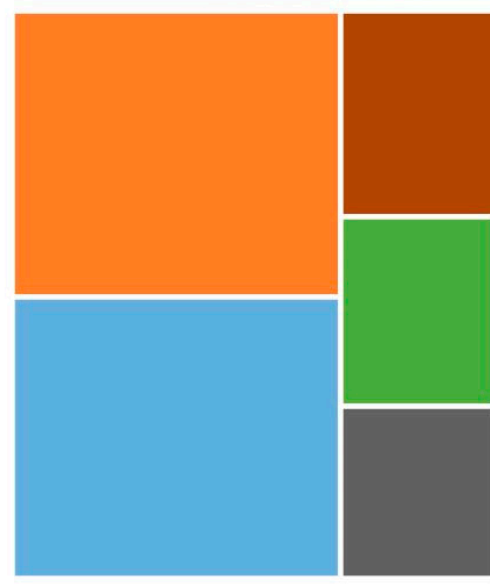

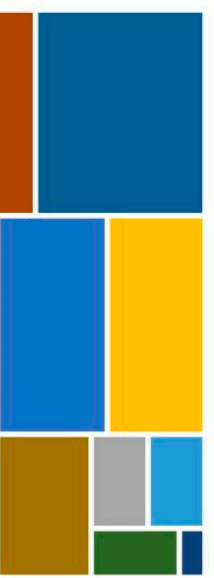

- AGR - IN_NMMI
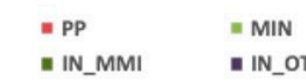

- IN_OTHMANUF

- IN_MMI

- IN_OTHMANUF $=\mathrm{CON}$

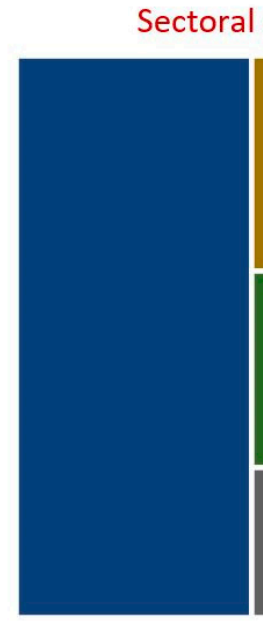

$$
\begin{aligned}
& \text { - IN_LIG } \\
& \text { - TRNS }
\end{aligned}
$$

= IN_PAP I RES-SERV

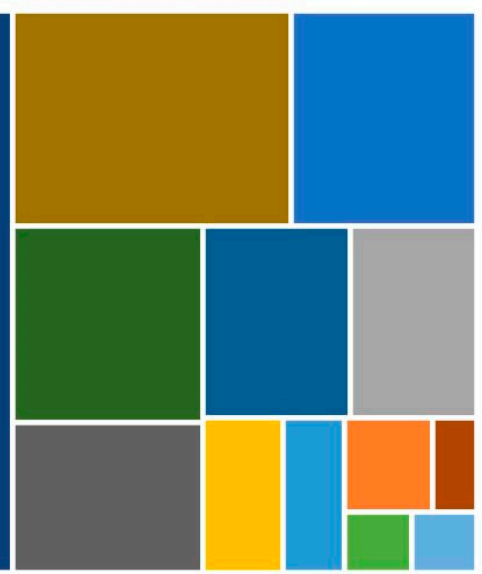

- IN_CHEM

Figure 10. Sectoral CFPs and eco-efficiency in UIS2012 scenario. (a) Sectoral CFPs, in UIS2012, $\mathrm{Mt} \mathrm{CO}_{2}$. (b) Sectoral eco-efficiency, in UIS2012, 10,000 CNY/t CO 2 . 


\subsection{Results Discussions}

According to the above findings, several insights are highlighted.

(1) Absolute mitigation vs. efficiency enhancement: for developing countries like China, with rapid industrialization and economic growth, it is inevitable to increase the absolute value of energy consumption and CFPs, even though technological advancement, cleaner production, and industrial symbiosis are promoted. However, we can gradually enhance the efficiency, to reduce the increasing rate of the absolute value of CFP, to realize a decouple between economic output and environmental impacts. Eco-efficiency, based on its definition, offers a tool to trace and monitor such progresses. In addition, the value of UIS is it offers a "second-round" CFP mitigation potential, apart from the energy efficiency enhancement. The results in Figures 8 and 9 verify such effects, even though the effects are moderate.

(2) Supply chain perspective: as we highlighted in the introduction section, the significant value of UIS is to make an innovation on the supply chain, by closing the material and energy flows loop. Change in one sector will drive to the change of other sectors in the supply chain, and such changes can be investigated with IOA.

(3) Planning and implementation perspective: in China at present, the most common existing UIS is bulky solid waste recycling and traditional waste recycling, simply because they are easily to operate. In this research, we designed some new UIS for the case city, but in reality, there needs to be further effort for their implementation, such as the negotiation between companies, governmental subsidies, supporting policies, and so on. Particularly, we had a monitor on the implementation progress in the year of 2018, summarized as below. We can notice that, until now, not all the designs were realized yet. In the future, to promote the final implementation, better business models (for example, the price mechanism for waste heat) and top-down governmental support (for example, subsidies and tax credits for recycling products), as well as more stable, compatible and standard technologies (to guarantee the stability of manufacturing process and supply chain), are critical factors.

- Recycle and reuse steel slag to substitute the raw materials required by cement production (scale is 120,000 tons/year): implemented;

- Recycle and reuse phosphorus slag to other industrial sectors, like cement production (500,000 tons/year): implemented;

- Recycle and reuse aluminum industry's slag to other industrial sectors, like cement production (400,000 tons/year): implemented, but smaller scale (200,000 tons/year);

- Recycle and reuse coal gangue to power plants (100,000 tons/year): implemented;

- Recycle and reuse coal flying ash (200,000 tons/year): implemented;

- Waste plastics recycling (10,000 tons/year): not implemented yet;

- Heat exchange (300 tons/year): not implemented yet; and

- Waste steel recycling (100,000 tons/year): implemented.

\section{Conclusions and Implications}

Urban industrial symbiosis as an innovative practice advancing regional eco-industrial development has been promoted for decades in developed countries like the Netherlands, Japan, and the USA. It is recognized to be an effective approach to improve the regional metabolism via optimizing the resource and energy flows in closed loops. However, its low-carbon benefits have been rarely reported in China. To further contribute to the policy implications in the "Post-Paris Era", this paper conducted, as a first try, an investigation into the impacts on sectoral eco-efficiency via urban industrial symbiosis implementation in one typical industrial city of China. Results revealed UIS could play the role to effectively offset the increased CFPs due to economic growth and urban expansion, and enabled enhancement of sectoral eco-efficiency as a whole. Compared to the BAU 
scenario of 2012, the UIS scenario with full implementation could mitigate around one $\mathrm{Mt} \mathrm{CO}_{2}$ in 2012 . The number was almost $3 \%$ of the whole urban $\mathrm{CO}_{2}$ emissions of Guiyang city in that year. The results also indicated that the sectoral CFPs and eco-efficiency had various features and highlighted different sectors. According to these findings, this paper hereby drew the following policy implications.

First of all, this paper verified that UIS could be an effective systematical innovation to support urban transition towards to sustainability. However, in real practice, UIS is seen as microlevel and practices among enterprises lack the full linkage to top-down urban planning. Actually, UIS itself is an industrial chain innovation, hereby has the potential to be incorporated into local industries' planning, and further link to urban planning policies. The authors strongly recommend consideration of this point for local planning strategy.

Secondly, trade-offs happen at the sectoral level (can be seen as a hidden cost of implementing UIS), hence it requires attention to strengthen the technical innovations supporting UIS, for example, issues of second pollution in the recycling process. Future efforts can include national circular technologies inventories compilation (to standardize the supporting technologies) and related secondary products' standard establishment are recommended to be promoted.

Thirdly, the eco-efficiency indicator was demonstrated to be an effective indicator to uncover the contribution and effects of UIS on sectors (part of our economic system), but it is not applied as useful indicator in real decision making yet, for example, the national and regional indicator on resource efficiency and eco-industrial parks' assessment index system. To advance its application, easier links to official statics and simple and standard calculation guidance should be promoted.

Last but not least, this research does have some research limitations to be tackled in the future.

a. IOA itself has the uncertainty, generated both by its assumption of unified products in each sector (not the real condition) and by the lack of city-level IOA. This research had to apply the province-level IOA to run the calculation in cities, increasing the results' uncertainty. Hence, there should be a compilation of a city-level IOT in future.

b. This research took only the CFPs as the environmental indicator in the eco-efficiency approach. In the future, more and integrated consideration of other environmental flows (resources and other emissions and wastes) are needed and beneficial. This requires future work on urban metabolism research under this topic.

c. IOA cannot fully reflect the interaction of sectors, hence, the sectoral eco-efficiency based on IOA has uncertainty. In the future, a more systematical analysis on the interaction of each sector, how UIS will change not only the monetary flows but also physical flows between sectors, is highly recommended.

d. This study applied eco-efficiency and CFP to analyze the contribution of UIS to urban sustainability. On the one hand, as a mature approach, eco-efficiency can partly present the enhancement of efficiency of the system. In this way, our results do highlight the benefit of UIS to urban sustainability, as we can observe that moderate increase in sectoral eco-efficiency. On the other hand, "efficiency" will also cover some information, for example, whether the absolute emissions reduce or not, and, if so, how about the scale? What about the economic cost and even the social costs as trade-offs? To answer such questions, future study on applying life cycle sustainability assessment (traditional life cycle environmental assessment, life cycle costing analysis, as well as social life cycle analysis) might be valuable. This is also some our on-going work.

Supplementary Materials: The following are available online at http://www.mdpi.com/2071-1050/12/9/3650/s1, Table S1: Summary of process data of the symbiotic network.

Author Contributions: Conceptualization, Y.B. and L.D.; methodology, L.D.; software, Z.L.; validation, Y.B., L.D. and Z.L.; formal analysis, Y.B.; investigation, L.D.; resources, L.Z.; data curation, L.D.; writing-original draft preparation, Y.B.; writing-review and editing, L.D. and Z.L.; visualization, Z.L.; supervision, L.Z.; project administration, L.D.; funding acquisition, L.D. and L.Z. All authors have read and agreed to the published version of the manuscript. 
Funding: This research was funded by [National Natural Science Foundation of China] grant number [41701636] And The APC was funded by [National Natural Science Foundation of China] grant number [41701636].

Acknowledgments: This study appreciates the support from National Natural Science Foundation of China (NSFC, No. 41701636).

Conflicts of Interest: The authors declare no conflict of interest.

\section{References}

1. Wang, Y.; Ren, H.; Dong, L.; Park, H.S.; Zhang, Y.; Xu, Y. Smart solutions shape for sustainable low-carbon future: A review on smart cities and industrial parks in China. Technol. Forecast. Soc. Chang. 2019, 144, 103-117. [CrossRef]

2. UN. World Urbanization Prospects The 2011 Revision 2012, United Nations, Department of Economic and Social Affairs; Population Division: New York, NY, USA, 2012.

3. Dong, L.; Fujita, T.; Zhang, H.; Dai, M.; Fujii, M.; Ohnishi, S.; Geng, Y.; Liu, Z. Promoting low-carbon city through industrial symbiosis: A case in China by applying HPIMO model. Energy Policy 2013, 61, 864-873. [CrossRef]

4. Wells, P.; Zapata, C. Renewable Eco-industrial Development. J. Ind. Ecol. 2012, 16, 665-668. [CrossRef]

5. Chen, M.; Liu, W.; Tao, X. Evolution and assessment on China's urbanization 1960-2010: Under-urbanization or over-urbanization? Habitat Int. 2013, 38, 25-33. [CrossRef]

6. Kim, H.W.; Dong, L.; Jung, S.; Park, H.S. The Role of the Eco-Industrial Park (EIP) at the national economy: An input-output analysis on Korea. Sustainability 2018, 10, 4545. [CrossRef]

7. Taddeo, R.; Simboli, A.; Ioppolo, G.; Morgante, A. Industrial Symbiosis, Networking and Innovation: The Potential Role of Innovation Poles. Sustainability 2017, 9, 169. [CrossRef]

8. Dong, L.; Gu, F.; Fujita, T.; Hayashi, Y.; Gao, J. Uncovering opportunity of low-carbon city promotion with industrial system innovation: Case study on industrial symbiosis projects in China. Energy Policy 2014, 65, 388-397. [CrossRef]

9. Berkel, R.V.; Fujita, T.; Hashimoto, S.; Fujii, M. Quantitative Assessment of Urban and Industrial Symbiosis in Kawasaki, Japan. Environ. Sci. Technol. 2009, 43, 1271-1281. [CrossRef]

10. Lombardi, D.R.; Laybourn, P. Redefining Industrial Symbiosis: Crossing academic-practitioner boundaries. J. Ind. Ecol. 2012, 16, 28-37. [CrossRef]

11. Kim, H.W.; Dong, L.; Choi, A.E.S.; Fujii, M.; Fujita, T.; Park, H.S. Co-benefit potential of industrial and urban symbiosis using waste heat from industrial park in Ulsan, Korea. Resour. Conserv. Recycl. 2018, 135, 225-234. [CrossRef]

12. Dong, L.; Liang, H.; Zhang, L.; Liu, Z.; Gao, Z.; Hu, M. Highlighting regional eco-industrial development: Life cycle benefits of an urban industrial symbiosis and implications in China. Ecol. Model. 2018, 361, 164-176. [CrossRef]

13. Fraccascia, L. Industrial Symbiosis and Urban Areas: A Systematic Literature Review and Future Research Directions. Procedia Environ. Sci. Eng. Manag. 2018, 5, 73-83.

14. Fujita, T.; Ohnishi, S.; Dong, L.; Fujii, M. Eco-industrial development as a circularization policy framework toward sustainable industrial cities. Lesson and suggestions from the eco town program in Japan. BDC 2014, $13,35-52$.

15. Dong, H.; Fujita, T.; Geng, Y.; Dong, L.; Ohnishi, S.; Sun, L.; Dou, Y.; Fujii, M. A review on eco-city evaluation methods and highlights for integration. Ecol. Indic. 2016, 60, 1184-1191. [CrossRef]

16. Li, H.; Dong, H.; Ren, J. Industrial symbiosis as a countermeasure for resource dependent city: A case study of Guiyang, China. J. Clean. Prod. 2015, 107, 252-266. [CrossRef]

17. Fang, K.; Dong, L.; Ren, J.; Zhang, Q.; Han, L.; Fu, H. Carbon footprints of urban transition: Tracking circular economy promotions in Guiyang, China. Ecol. Model. 2017, 365, 30-44. [CrossRef]

18. Dong, L.; Zhang, H.; Fujita, T.; Ohnishi, S.; Li, H.; Fujii, M.; Dong, H. Environmental and economic gains of industrial symbiosis for Chinese iron/steel industry: Kawasaki's experience and practice in Liuzhou and Jinan. J. Clean. Prod. 2013, 59, 226-238. [CrossRef]

19. Zhang, C.; Hu, M.; Dong, L.; Gebremariam, A.; Mirand-Xicotencatl, B.; di Maio, F.; Tukker, A. Eco-efficiency assessment of technological innovations in high-grade concrete recycling. Resour. Conserv. Recycl. 2018, 149, 649-663. [CrossRef] 
20. Zhang, H.; Dong, L.; Li, H.; Fujita, T.; Ohnishi, S.; Tang, Q. Analysis of low-carbon industrial symbiosis technology for carbon mitigation in a Chinese iron/steel industrial park: A case study with carbon flow analysis. Energy Policy 2013, 61, 1400-1411. [CrossRef]

21. Courtonne, J.Y.; Alapetite, J.; Longaretti, P.Y.; Dupré, D.; Prados, E. Downscaling material flow analysis: The case of the cereal supply chain in France. Ecol. Econ. 2015, 118, 67-80. [CrossRef]

22. Yu, C.; Dijkema, G.P.; De Jong, M.; Shi, H. From an eco-industrial park towards an eco-city: A case study in Suzhou, China. J. Clean. Prod. 2015, 102, 264-274. [CrossRef]

23. Yu, Y.; Wu, W.; Zhang, T.; Liu, Y. Environmental catching-up, eco-innovation, and technological leadership in China's pilot ecological civilization zones. Technol. Forecast. Soc. Chang. 2016, 112, 228-236. [CrossRef]

24. Dong, L.; Fujita, T.; Dai, M.; Geng, Y.; Ren, J.; Fujii, M.; Wang, Y.; Ohnishi, S. Towards preventative eco-industrial development: An industrial and urban symbiosis case in one typical industrial city in China. J. Clean. Prod. 2016, 114, 387-400. [CrossRef]

25. Giljum, S.; Hubacek, K. Conceptual Foundations and Applications of Physical Input-Output Tables, in Handbook of Input-Output Economics in Industrial Ecology; Suh, S., Ed.; Springer: Dordrecht, The Netherlands, 2009; pp. 1-75.

26. Leontief, W. Quantitative input-output relations in the economic system. Rev. Econ. Stat. 1936, 18, 105-125. [CrossRef]

27. Mi, Z.; Zhang, Y.; Guan, D.; Shan, Y.; Liu, Z.; Cong, R.; Yuan, X.C.; Wei, Y.M. Consumption-based emission accounting for Chinese cities. Appl. Energy 2016, 184, 1073-1081. [CrossRef]

28. Chen, G.; Wiedmann, T.; Wang, Y.; Hadjikakou, M. Transnational city carbon footprint networks—Exploring carbon links between Australian and Chinese cities. Appl. Energy 2016, 184, 1082-1092. [CrossRef]

29. Hertwich, E.G.; Peters, G.P. Carbon Footprint of Nations: A Global, Trade-Linked Analysis. Environ. Sci. Technol. 2009, 43, 6414-6420. [CrossRef]

30. Dou, Y.; Togawa, T.; Dong, L.; Fujii, M.; Ohnishi, S.; Tanikawa, H.; Fujita, T. Innovative planning and evaluation system for district heating using waste heat considering spatial configuration: A case in Fukushima, Japan. Resour. Conserv. Recycl. 2018, 128, 406-416. [CrossRef]

31. Chertow, M.R. "Uncovering” Industrial Symbiosis. J. Ind. Ecol. 2007, 11, 11-30. [CrossRef]

32. Chertow, M.; Ehrenfeld, J. Organizing Self-Organizing Systems. J. Ind. Ecol. 2012, 16, 13-27. [CrossRef]

33. Van Berkel, R. Quantifying Sustainability Benefits of Industrial Symbioses. J. Ind. Ecol. 2010, 14, 371-373. [CrossRef]

34. Van Berkel, R.; Fujita, T.; Hashimoto, S.; Geng, Y. Industrial and urban symbiosis in Japan: Analysis of the Eco-Town program 1997-2006. J. Environ. Manag. 2009, 90, 1544-1556. [CrossRef] [PubMed]

35. Park, H.-S.; Won, J.-Y. Ulsan Eco-industrial Park: Challenges and Opportunities. J. Ind. Ecol. 2007, 11, 11-13. [CrossRef]

36. Gu, Y.; Wu, Y.; Liu, J.; Xu, M.; Zuo, T. Ecological civilization and government administrative system reform in China. Resour. Conserv. Recycl. 2020, 155, 104654. [CrossRef]

37. Wiedmann, T. Editorial: Carbon Footprint and Input-Output Analysis. Econ. Syst. Res. 2009, 21, $175-186$. [CrossRef]

38. IPCC. Climate Change 2013: The Physical Science Basis. IPCC, Working Group I Contribution to the IPCC Fifth Assessment Report (AR5); IPCC (Intergovernmental Panel on Climate Change): Geneva, Switzerland; Cambridge University Press: New York, NY, USA, 2013.

(C) 2020 by the authors. Licensee MDPI, Basel, Switzerland. This article is an open access article distributed under the terms and conditions of the Creative Commons Attribution (CC BY) license (http://creativecommons.org/licenses/by/4.0/). 